\title{
Gender differences in the prevalence, clinical features and response to cabergoline in hyperprolactinemia
}

\author{
Annamaria Colao, Antonella Di Sarno, Paolo Cappabianca ${ }^{1}$, Francesco Briganti ${ }^{2}$, Rosario Pivonello, \\ Carolina Di Somma, Antongiulio Faggiano, Bernadette Biondi and Gaetano Lombardi \\ Departments of Molecular and Clinical Endocrinology and Oncology, Section of Endocrinology and Neurological Sciences, ${ }^{1}$ Section of Neurosurgery and \\ ${ }^{2}$ Section of Neuroradiology, 'Federico II' University of Naples, via S. Pansini 5, 80131 Naples, Italy \\ (Correspondence should be addressed to Annamaria Colao; Email: colao@unina.it)
}

\begin{abstract}
Background: Gender differences in tumor size are supposed to exist in hyperprolactinemia since microadenomas are more commonly found in women and macroadenomas in men. Whether this reflects only a delay in diagnosis in men or a true gender difference in tumor pathogenesis is still unclear. Objective: To prospectively analyze gender differences in the presentation and response to cabergoline treatment in 219 consecutive newly diagnosed patients with hyperprolactinemia.

Design: An open prospective design.

Subjects: Of the 219 patients of which 145 were women; 107 patients had macroprolactinoma, 97 had microprolactinoma, and 15 had non-tumoral hyperprolactinemia.

Methods: Presenting clinical symptoms, prolactin levels and tumor size at magnetic resonance imaging were measured before and 3-6 months after cabergoline therapy.

Results: Prevalence of microprolactinomas ( $56 \%$ vs $22 \%, P=<0.0001)$ and non-tumoral hyperprolactinemia $(10 \%$ vs $0 \%, P=0.01)$ was higher in women than in men. Men and women were of similar age (median 32 vs 29 years; $P=0.2$ ) and a similar number had gonadal/sexual dysfunction ( 85 vs $83 \%, P=0.6)$; weight gain $(70$ vs $46 \% ; P=<0.0001)$ and galactorrhea (52 vs $19 \%$; $P=<0.0001)$ were more common in women. Prolactin levels were higher in men than in women, whether exhibiting macro- $(2848 \pm 2954$ vs $1132 \pm 2351 \mu \mathrm{g} / \mathrm{l}, P=<0.0001)$ or microadenomas $(187.8 \pm 51.8$ vs $135.4 \pm 60.5 \mu \mathrm{g} / \mathrm{l}, P=0.009)$ and the size of the adenoma was larger in men than in women irrespective of macro- $(25.8 \pm 12.4 \mathrm{vs} 17.2 \pm 7.2 \mathrm{~mm}, P=<0.0001)$ or microadenoma diagnosis $(8.0 \pm 1.4$ vs $7.1 \pm 1.6 \mathrm{~mm}, P=0.04)$. After treatment, prolactin levels decreased by $89.2-96.4 \%$ in all groups, and normalized more frequently in micro- than in macroadenoma patients ( 86 vs $64 \%, P<0.0001)$, regardless of gender $(70 \%$ vs $69 \%, P=0.9)$. Menses resumed in $82 \%$ of women, libido disturbances improved in $57 \%$ of men. Tumor size was reduced by $45 \pm 25 \%$ and $52 \pm 24 \%$ in macroprolactinoma patients and by $44 \pm 31$ and $38 \pm 29 \%$ in microprolactinoma patients in women and men respectively. Visual field defects disappeared in $61 \%$ of women and in $71 \%$ of men $(P=0.6)$.

Conclusions: Prevalence of macroprolactinomas was similar in men and women; microprolactinomas and non-tumoral hyperprolactinemia were more frequent in women. Clinical symptoms at presentation differed according to gender, with galactorrhea and weight gain more frequent in women. The successful response to cabergoline treatment for 6 months was higher in micro- than in macroprolactinoma patients and was similar in women and men.
\end{abstract}

European Journal of Endocrinology 148 325-331

\section{Introduction}

Gender differences in tumor size are supposed to exist in hyperprolactinemia since microadenomas are more commonly found in women and macroadenomas in men. Whether this reflects merely a delay in diagnosis in men or a true gender difference in tumor pathogenesis is still unclear. In fact, even minor elevations in serum prolactin levels often lead to symptoms of ovulatory dysfunction and/or galactorrhea, facilitating early diagnosis in women (1). Conversely, in men hypogonadism with decreased libido, sexual dysfunction, and abnormal semen analysis as manifestations of prolactin hypersecretion are often misunderstood and thus the diagnosis is often delayed (2-5). Delay in diagnosis was suggested not to be the only difference between men and women, since rapidly growing prolactinomas with increased markers of cellular proliferation have recently been reported to occur more often in men $(6,7)$. This suggests that men could have more aggressive prolactinomas 
than women. Additionally, since the prevalence of hyperprolactinemia is much higher in women, the efficacy of pharmacotherapy has predominantly, if not exclusively, been proven in women $(2,8,9)$, while data in men are still limited. The possibility that men having more aggressive prolactinomas respond less to pharmacotherapy than women has never been investigated.

The aim of this prospective study was to investigate gender differences in the etiology, clinical, biochemical and radiological presentation and response to longterm cabergoline therapy in a large series of consecutive newly diagnosed patients with hyperprolactinemia.

\section{Subjects and methods}

\section{Patients}

From 1996 to 2000, 219 consecutive newly diagnosed patients (145 women and 76 men; aged $15-72$ years) were admitted to our Department for hyperprolactinemia and were all included in this study after their informed consent had been obtained. Data from 120 patients had previously been reported (10-12).
Inclusion criteria were: for macroprolactinomas serum prolactin levels $\geq 200 \mu \mathrm{g} / \mathrm{l}$ and a pituitary tumor $\geq 1 \mathrm{~cm}$ in diameter on pituitary magnetic resonance imaging (MRI); for microprolactinomas serum prolactin levels $\geq 50 \mu \mathrm{g} / \mathrm{l}$ and a pituitary tumor $<1 \mathrm{~cm}$ in diameter; for non-tumoral hyperprolactinemia serum prolactin levels above the normal range and a normal pituitary at MRI, with no other explanation for increased prolactin such as primary hypothyroidism or drug-induced hyperprolactinemia. Based on these criteria, 107 patients had macroprolactinomas (49 women), 97 had microprolactinomas (81 women), and 15 women had non tumoral hyperprolactinemia (Table 1).

\section{Study protocol}

Patients with hypopituitarism received standard replacement therapy with L-thyroxine $(50-100 \mu \mathrm{g}$ p.o. daily), cortisone acetate $(25-37.5 \mathrm{mg} /$ day), and vasopressin (5-20 $\mu \mathrm{g} /$ day), where necessary. In macroprolactinoma patients only, growth hormone (GH) deficiency was investigated by low insulin-like growth

Table 1 Patients' profile at study entry. Data are shown as means \pm s.D. Presenting symptoms are expressed as number of individual patients with prevalence in parentheses.

\begin{tabular}{|c|c|c|c|}
\hline & Women & Men & $P$ \\
\hline $\begin{array}{l}\text { Total number } \\
\text { Median age (years (mean } \pm \text { S.D.)) }\end{array}$ & $\begin{array}{l}145 \\
29(32.2 \pm 11.5)\end{array}$ & $\begin{array}{l}74 \\
32(35.0 \pm 13.5)\end{array}$ & $\begin{array}{l}<0.0001 \\
0.1\end{array}$ \\
\hline $\begin{array}{l}\text { Macroprolactinoma } \\
\text { Age median (years) } \\
\text { Basal prolactin levels }(\mu \mathrm{g} / \mathrm{l}) \\
\text { Maximal tumor diameter }(\mathrm{mm}) \\
\text { Patients with pituitary hormone deficiency }(n) \\
\text { Patients with visual field defects }(n) \\
\text { Headache }(n) \\
\text { Galactorrhea }(n)^{\star} \\
\text { Infertility }(n)^{\star \star} \\
\text { Menstrual disturbances }(n)^{\star * *} \\
\text { Libido disturbances }(n) \\
\text { Weight gain }(n)\end{array}$ & $\begin{array}{l}49 \\
33(36 \pm 14) \\
1132 \pm 2351 \\
17.2 \pm 7.2 \\
25(51 \%) \\
18(37 \%) \\
34(69 \%) \\
37(75 \%) \\
12(24 \%) \\
38(100 \%) \\
/ \\
46(94 \%)\end{array}$ & $\begin{array}{l}58 \\
33(36 \pm 14) \\
2848 \pm 2954 \\
25.8 \pm 12.4 \\
34(59 \%) \\
28(48 \%) \\
22(38 \%) \\
13(22 \%) \\
11(19 \%) \\
/ \\
48(83 \%) \\
31(53 \%)\end{array}$ & $\begin{array}{l}0.2 \\
0.9 \\
0.001 \\
<0.0001 \\
0.4 \\
0.6 \\
0.02 \\
<0.0001 \\
0.8 \\
\quad / \\
/ \\
<0.0001\end{array}$ \\
\hline $\begin{array}{l}\text { Microprolactinoma } \\
\text { Age median (years) } \\
\text { Basal prolactin levels }(\mu \mathrm{g} / \mathrm{l}) \\
\text { Maximal tumor diameter }(\mathrm{mm}) \\
\text { Headache }(n) \\
\text { Galactorrhea }(n) \\
\text { Infertility }(n)^{\star \star} \\
\text { Menstrual disturbances }(n)^{\star \star \star \star} \\
\text { Libido disturbances }(n) \\
\text { Weight gain }(n)\end{array}$ & $\begin{array}{l}81 \\
28(30 \pm 10) \\
135.4 \pm 60.5 \\
7.1 \pm 1.6 \\
25(31 \%) \\
35(43 \%) \\
43(54 \%) \\
62(76 \%) \\
/ \\
48(59 \%)\end{array}$ & $\begin{array}{l}16 \\
28.5(31 \pm 11) \\
187.8 \pm 51.8 \\
8.0 \pm 1.4 \\
1(6 \%) \\
0(0 \%) \\
3(19 \%) \\
/ \\
14(88 \%) \\
3(19 \%)\end{array}$ & $\begin{array}{l}0.001 \\
0.7 \\
0.002 \\
0.04 \\
0.08 \\
0.003 \\
0.02 \\
1 \\
1 \\
0.03\end{array}$ \\
\hline $\begin{array}{l}\text { Non tumoral hyperprolactinemia } \\
\text { Age median (years) } \\
\text { Basal prolactin levels }(\mu \mathrm{g} / \mathrm{l}) \\
\text { Headache }(n) \\
\text { Galactorrhea }(n) \\
\text { Infertility }(n) \\
\text { Menstrual disturbances }(n) \\
\text { Weight gain }(n)\end{array}$ & $\begin{array}{l}15 \\
28(31 \pm 8) \\
72 \pm 9 \\
0(0 \%) \\
3(20 \%) \\
5(33 \%) \\
12(80 \%) \\
8(53 \%)\end{array}$ & $\begin{array}{l}0 \\
1 \\
1 \\
1 \\
1 \\
1 \\
1 \\
1\end{array}$ & $\begin{array}{l}0.0001 \\
\text { n.a. } \\
\text { n.a. } \\
\text { n.a. } \\
\text { n.a. } \\
\text { n.a. } \\
\text { n.a. } \\
\text { n.a. }\end{array}$ \\
\hline
\end{tabular}

${ }^{\star}$ Either spontaneous or expressible; ${ }^{* \star}$ as presenting complaint; ${ }^{\star \star \star} 11$ women were excluded since they were $\geq 50$ years of age; ${ }^{\star \star \star \star} 4$ women were excluded since they were $\geq 50$ years of age. n.a., not applicable. 
factor-I (IGF-I) levels for age in the absence of liver or renal failure or, when IGF-I levels were normal, by a $\mathrm{GH}$ peak $\leq 9 \mu \mathrm{g} / \mathrm{l}$ after arginine plus $\mathrm{GH}-$ releasing hormone administration (13, 14). Serum free thyroid hormones, and serum and urinary $\mathrm{Na}^{+}$ and $\mathrm{K}^{+}$measurements periodically assessed adequacy of hormone replacement therapy. At study entry, serum prolactin levels were calculated as the average value of a 6 -h profile by blood sampling every $30 \mathrm{~min}$ (0800-1400 h). After 1, 3 and 6 months of treatment, prolactin levels were assayed at 0800, 0815 and $0830 \mathrm{~h}$ and the average value was taken for statistical analysis. A general clinical examination was performed every month for the first 3 months and then after 6 months. The following symptoms and signs were specifically investigated in all patients: visual field defects, visual loss, headache, galactorrhea, weight gain, sexual dysfunction, gonadal dysfunction, and infertility. Loss of libido was evaluated only in men since this symptom is hardly assessed in women.

\section{Treatment protocol}

To all patients, except one with microadenoma (a woman) and three with macroprolactinoma (all men), cabergoline was the first line therapy. Another man with macroprolactinoma underwent an operation after four months of cabergoline treatment because he developed rhinorrhea (15), and was thus excluded from the analysis. In accordance with a previous study (12), in patients with microprolactinoma and non-tumoral hyperprolactinemia treatment was administered orally at a starting dose of $0.25 \mathrm{mg}$ once weekly for the first week, twice weekly during the second week, and then $0.5 \mathrm{mg}$ twice weekly. Dose adjustment was carried out every 2 months on the basis of prolactin suppression: the dose was increased when hormone levels were $>25 \mu \mathrm{g} / \mathrm{l}$ in women or $>15 \mu \mathrm{g} / \mathrm{l}$ in men. In macroprolactinoma patients the starting dose of cabergoline was $0.5 \mathrm{mg}$ once a week for the first week, then twice weekly. Dose adjustment was performed as above. In patients not normalizing prolactin levels, the cabergoline dose was progressively increased to a maximum of $3.5 \mathrm{mg} /$ week. All patients were followed for 6 months.

\section{Imaging studies}

Tumor mass was evaluated by MRI as previously reported (10-12). MRI studies were performed on clinical $0.5 \mathrm{~T}$ and $1 \mathrm{~T}$ scanners, using $\mathrm{T} 1$ weighted gradient recalled-echo (repetition time 200-300 ms; echo time 10-12 ms; flip angle $90^{\circ}, 4$ signal averages) in the sagittal and coronal planes. The acquisitions were repeated before and after the administration of $0.1 \mathrm{mmol}$ gadolinium chelate. MRI was performed before and after 3 and 6 months of treatment in all macroprolactinoma patients and before and after 6 months in microprolactinoma patients. All tumor diameters were measured and the maximal tumor diameter (expressed in $\mathrm{mm}$ ) was considered in all macro- and microadenoma patients for further analysis. According to a previous study (12), tumor shrinkage was evaluated as the reduction of the maximal tumor diameter compared with baseline by a semi-quantitative fourpoint scale as follows: $<10 \%$, absent; $10-20 \%$, mild; $20-30 \%$, moderate; $>30 \%$, remarkable.

\section{Visual perimetry}

In all patients with macroprolactinoma the assessment of visual field defects, by Goldmann-Friedmann perimetry, and visual acuity was performed at baseline. The ophthalmological examination was repeated after three and six months in the 35 patients with quadrantopia/hemianopia and every week for the first month then every month in the 11 with more severe visual field defects and in the four with visual loss.

\section{Assays}

Serum follicle-stimulating hormone (FSH), luteinizing hormone (LH), and prolactin (PRL) levels were assessed by radioimmunoassay using commercial kits. Testosterone levels were assessed using Immulite solid phase chemiluminescent enzyme immunoassay using commercial kits. Normal ranges in our laboratory were: FSH and LH 5-15 IU/l; testosterone in men 3-9 $\mu \mathrm{g} / \mathrm{l}$; prolactin $5-25 \mu \mathrm{g} / \mathrm{l}$ in women and $5-15 \mu \mathrm{g} / \mathrm{l}$ in men.

\section{Statistical analysis}

Data are reported as means \pm S.D. The statistical analysis was performed by means of the SPSS Inc. (Cary, NC, USA) package using the analysis of variance. Statistical significance was set at 5\%. Correlations were performed by calculating the Pearson's coefficient. The $\chi^{2}$ test was also used where appropriate.

\section{Results}

During this five year prospective study, the overall prevalence of non-tumoral hyperprolactinemia (6.8\%) was significantly lower than that of macroprolactinomas (49\%) and microprolactinomas (44\%; P $<0.0001)$. Macroprolactinomas were equally frequent in women and men ( 45 vs $54 \% ; P=0.2$ ) while microprolactinomas $(83.5$ vs $16.4 \% ; P<0.001)$ and non-tumoral hyperprolactinemia (100 vs $0 \%, P<0.0001)$ were more frequent in women (Table 1).

\section{Profile at study entry}

Baseline clinical characteristics in men and women are shown in Table 1. Among macroprolactinoma patients, $46(43 \%)$ had visual field defects without gender 
difference. A larger proportion of women with macroprolactinoma reported a history of moderate-to-severe headache, and in the entire population women exhibited weight gain more frequently (Table 1). Galactorrhea (in macro- and microprolactinoma patients) and infertility (only in microprolactinoma patients) were also more frequent in women (Table 1). Prolactin levels were significantly higher in men than in women bearing either macro- or microadenomas (Table 1); they were highly correlated with the maximal tumor diameter in the entire population (Fig. 1), and in women $(r=0.7, \quad P<0.001)$ and men $(r=0.9, P<0.001)$ separately. The age of the patients was not correlated with either basal PRL levels or basal tumor size in micro- $(r=0.03$ and $r=0.1$ respectively; $P>0.05$ ) and in macroprolactinoma patients $(r=0.14$ and $r=0.13$ respectively; $P>0.05$ ). Hypopituitarism, apart from hypogonadism, was present in $48 \%$ of women and $48 \%$ of men with macroadenoma; GH deficiency was more frequent $(80 \%)$ than thyrotropin $(47 \%)$ and corticotropin deficiency $(23 \%)$. None of the 97 patients with microadenoma had other pituitary hormone deficiencies apart from hypogonadism - low FSH and LH levels were found in 23 women (28\%) and seven men $(44 \% P=0.4)$. Testosterone deficiency was present in 48 men with macro- $(82 \%)$ and eight with microadenoma $(50 \% ; P=0.02)$. The size of the adenomas was larger in men than in women with macroprolactinoma $(P<0.0001)$ or microprolactinoma $(P=0.04$, Table 1$)$.

\section{Six-month follow-up analysis}

A decrease in prolactin levels was found both in microprolactinoma (from $144 \pm 62$ to $14.4 \pm 21.5 \mu \mathrm{g} / \mathrm{l}$,

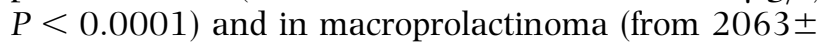
2816 to $71 \pm 208 \mu \mathrm{g} / \mathrm{l}, P<0.0001)$ patients. Prolactin

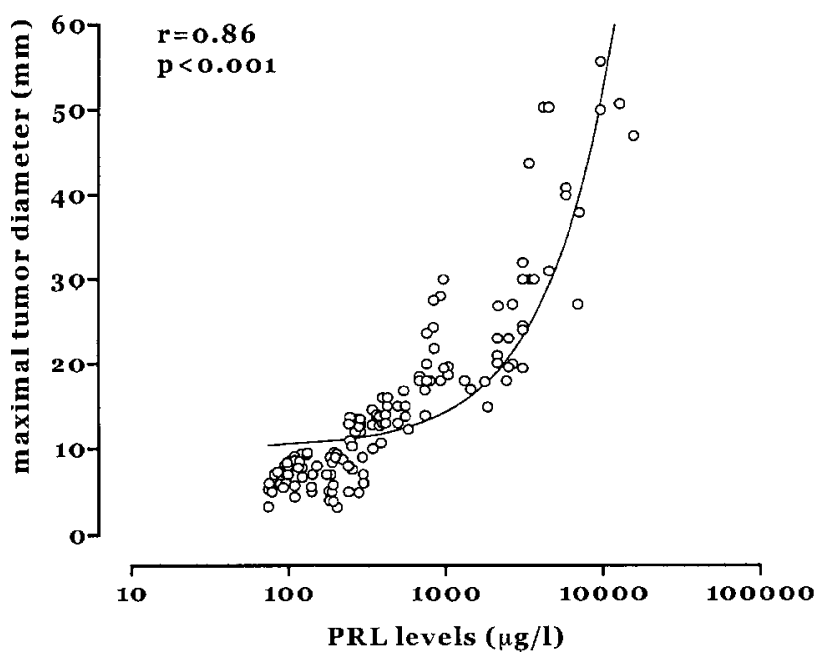

Figure 1 Results of the correlation analysis between maximal diameter of the prolactinoma and prolactin levels at baseline. levels normalized more frequently in micro- than in macroadenoma patients $(86 \%$ vs $64 \%, P<0.0001)$, without a gender difference $(70 \%$ vs $69 \%, P=0.9)$, and in all women with non-tumoral hyperprolactinemia (Table 2). In particular, to normalize PRL levels among the 68 macroprolactinoma patients, $17(25 \%)$ and 1 (1.5\%) required an increase in cabergoline dose to 1.5 and $2 \mathrm{mg} /$ week respectively, while 42 continued the treatment at the dose of $1 \mathrm{mg}$ /week and the remaining $8(11.7 \%)$ could reduce the dose to $0.5 \mathrm{mg} /$ week; among the 84 microprolactinoma patients 55 (65.5\%) continued the treatment at the dose of $1 \mathrm{mg} /$ week and the remaining $29(34.5 \%)$ could reduce the dose to $0.5 \mathrm{mg} /$ week. Menses resumed in 92 women $(82 \%)$, libido disturbances improved in 36 men (58\%). The sizes of both macro- and microprolactinomas were reduced by $38 \pm 29 \%$ to $52 \pm 24 \%$ (Table 2 ). There was no difference in the amount of tumor shrinkage between men and women. In detail, following the semi-quantitative scale and in macro- and microprolactinoma patients respectively, no shrinkage was observed in five $(4.5 \%)$ and $14(14.4 \%)$, mild shrinkage occurred in seven $(6.5 \%)$ and $16(16.5 \%)$; moderate shrinkage in 19 $(17.8 \%)$ and $15(15.5 \%)$ and notable shrinkage in 76 $(71 \%)$ and $52(53.6 \%)$ patients. The prevalence of notable tumor shrinkage was higher in macro- than in microprolactinomas $\left(\chi^{2}=5.9 ; \quad P=0.015\right)$. Nine patients with macroprolactinoma (4 women) and 14 with microprolactinoma (12 women) had tumor disappearance. No patient had evidence of any increase in tumor size during therapy. Visual field defects disappeared in $61 \%$ of women and in $71 \%$ of men $(P=$ $0.6)$; headache disappeared in $82 \%$ of men and in $61 \%$ of women with macroprolactinoma $(P=0.08)$ and in $96 \%$ of women with microprolactinoma. Menses resumed in $82 \%$ of women, libido disturbances improved in $57 \%$ of men with macro- or microprolactinoma. In hypopituitary patients with macroprolactinoma, replacement therapy remained unchanged during treatment except for three patients with macroprolactinomas who withdrew from cortisone replacement; no GH replacement was given during the study period.

In the 204 patients with adenoma, basal prolactin levels were correlated with prolactin levels after 6 months of treatment (Fig. 2) and basal tumor size was correlated with tumor size after 6 months of treatment (Fig. 3). The dose of cabergoline was correlated with prolactin levels at baseline $(r=0.2, P=0.001)$ and after 6 months $(r=0.5, P<0.0001)$, as well as with tumor size at baseline $(r=0.4, P<0.0001)$ and after 6 months $(r=0.5, P<0.0001)$.

Side effects were very mild and infrequent; only six patients had side effects (two men and four women) and these were, most commonly, nausea, postural hypotension and drowsiness after the dose of $3 \mathrm{mg}$ cabergoline/week. No patient was withdrawn from treatment because of side effects. 
Table 2 Efficacy of a 6-month treatment with cabergoline on prolactin levels and tumor size according to gender. Data are shown as means \pm S.D.

\begin{tabular}{|c|c|c|c|c|c|c|c|c|c|}
\hline & \multicolumn{3}{|c|}{ Macroprolactinomas } & \multicolumn{3}{|c|}{ Microprolactinomas } & \multicolumn{3}{|c|}{$\begin{array}{c}\text { Non tumoral } \\
\text { hyperprolactinemia }\end{array}$} \\
\hline & Women & Men & $P$ & Women & Men & $P$ & Women & Men & $P$ \\
\hline Number & 49 & 58 & 0.5 & 81 & 16 & 0.7 & 15 & 0 & 0.0001 \\
\hline Basal prolactin levels $(\mu \mathrm{g} / \mathrm{l})$ & $1132 \pm 2351$ & $2848 \pm 2954$ & 0.001 & $135.4 \pm 60.5$ & $187.7 \pm 51.8$ & 0.002 & $71.6 \pm 2.3$ & I & n.a. \\
\hline 6-month prolactin levels $(\mu \mathrm{g} / \mathrm{l})$ & $59.9 \pm 148.5$ & $80.0 \pm 248.8$ & 0.6 & $14.6 \pm 21.9$ & $13.5 \pm 20.0$ & 0.8 & $5.2 \pm 1.1$ & I & n.a. \\
\hline Prolactin decrease (\%) & $93.4 \pm 9.7$ & $96.4 \pm 6.4$ & 0.06 & $89.2 \pm 14.5$ & $92.6 \pm 10.0$ & 0.4 & $92.5 \pm 1.7$ & I & n.a. \\
\hline Maximal tumor diameter (mm) & $17.2 \pm 7.2$ & $25.8 \pm 12.4$ & $<0.0001$ & $7.1 \pm 1.6$ & $8.0 \pm 1.4$ & 0.04 & l & I & n.a. \\
\hline 6-month tumor diameter (mm) & $9.8 \pm 6.6$ & $12.7 \pm 8.7^{\star}$ & 0.07 & $4.2 \pm 2.2^{* *}$ & $4.9 \pm 2.6$ & 0.2 & l & I & n.a. \\
\hline Maximal tumor decrease (\%) & $45.0 \pm 25.1$ & $52.1 \pm 23.6$ & 0.1 & $43.6 \pm 31.3$ & $37.6 \pm 28.6$ & 0.5 & I & I & n.a. \\
\hline Dose median (mg/week) & 1 & 1.5 & 0.5 & 1 & 1 & 0.9 & 0.5 & I & n.a. \\
\hline Dose range (mg/week) & $0.5-3.5$ & $0.5-3.0$ & 0.5 & $0.5-3.5$ & $0.5-3.0$ & 0.9 & $0.25-0.5$ & I & n.a. \\
\hline
\end{tabular}

*Four patients were excluded because of surgical approach before or during cabergoline treatment; ** One patient was excluded because of surgical approach before cabergoline treatment. n.a., not applicable.

\section{Discussion}

We performed a 5-year prospective study of 219 patients with hyperprolactinemia in order to assess gender differences in the etiology, clinical characteristics and cabergoline treatment success. Non tumoral hyperprolactinemia was significantly less frequent than micro- and macroprolactinomas. Microprolactinomas were more frequent in women while macroprolactinomas were equally distributed in women and men. Interestingly, no man was diagnosed as bearing nontumoral hyperprolactinemia. Clinical symptoms at presentation differed according to gender: infertility, galactorrhea, headache and weight gain were more frequent in women. Prolactin normalization after a 6-month cabergoline treatment was higher in microthan in macroprolactinoma patients, without any difference according to gender. Similarly, there was no gender difference in cabergoline dosage required for therapeutic success.

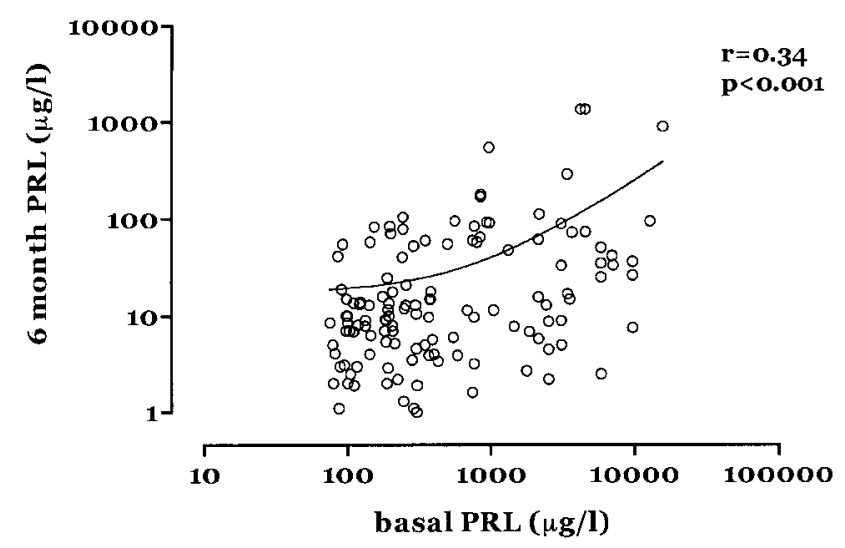

Figure 2 Results of the correlation analysis between prolactin levels at baseline and after 6 months of cabergoline treatment in the 204 patients with pituitary tumors.
Data on hyperprolactinemia in men are still limited compared with women and have usually been analyzed in small retrospective studies $(5,7,16-23)$ with only one exception (24). There was no significant difference in the age at presentation in men with macro- compared with microprolactinomas in our series, but women with microprolactinoma were significantly younger than those with macroprolactinoma. Age at presentation in our men was slightly lower than that reported by Berezin et al. (22), Walsh \& Pullan (20) and Pinzone et al. (6) who found a mean age of 40 years or older. The attention given to symptoms suggestive of hyperprolactinemia is likely higher today than previously. We also found, as expected, that hypopituitarism, visual field defects and headache were more frequent chief complaints of patients with macroprolactinoma than of those with microprolactinoma. Surprisingly, however, headache and weight gain were significantly more frequent in women than in men despite having similar prolactin values. Weight gain is indeed associated with hyperprolactinemia $(25-28)$ but it has been suggested that it is

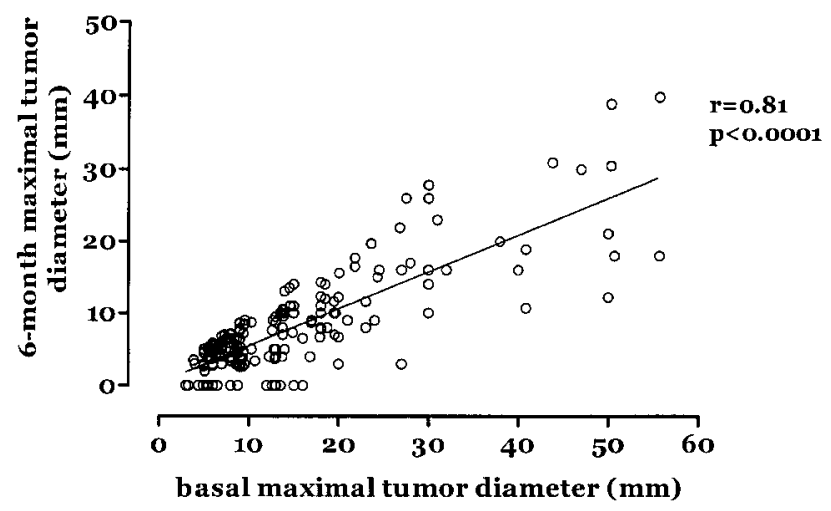

Figure 3 Results of the correlation analysis between tumor size at baseline and after 6 months of cabergoline treatment in the 204 patients with pituitary tumors. 
more frequent in men $(29,30)$, at partial variance with our results. It should be noted, however, that the only study focusing on weight gain according to gender was retrospective (30).

Microprolactinomas are found, almost invariably, more frequently in women, while it is still questioned whether macroprolactinomas are more frequent in men. In fact, some studies have reported an equal distribution of macroprolactinomas between genders (12, 31, 32 , this study), others have found higher prevalence in men $(33,34)$ or in women $(10,35)$. In previous studies $(7,19)$ tumor size did not seem to be associated with the duration of symptoms; we did not analyze the duration of symptoms referable to hyperprolactinemia, and patients' age was not correlated with tumor size in either micro- or macroprolactinoma patients. It has been suggested that prolactinomas have more aggressive growth characteristics in men compared with women (7) since markers of cellular proliferation, such as Ki67 and proliferating cell nuclear antigen, have been shown to be expressed more in prolactinomas from men than from women $(6,7)$. However, even if the possibility that gender-related factors modifying the rate of tumor growth cannot be ruled out by the results of this study, we did not find any difference between the prevalence and severity of neurological signs, as an expression of tumor invasiveness, according to gender. We only found that men had larger tumors, correlated with higher prolactin levels, than women. The increased tumor size in men, however, seems more likely to be due to the inability to detect early sexual dysfunction leading to a delay in diagnosis. This hypothesis also fits with the absence of non-tumoral hyperprolactinemia in men.

Additionally, treatment outcome, evaluated according to etiology, was similar in men and women; these data support the concept that cabergoline is an effective prolactin lowering drug in men as in women. The prevalence and entity of tumor shrinkage was also similar in women and men. Prolactin normalization resulted in a normal serum testosterone level in $84 \%$ of men, in accordance with previous findings (3). However, sexual dysfunction remained symptomatic despite normalization of prolactin and testosterone levels in $43 \%$ of men. These findings indicate that surveillance of sexual dysfunction symptoms is required in all men with prolactinomas.

In the largest retrospective study so far reported, Verhelst et al. (24) indicated six parameters potentially useful in the prediction of treatment success: initial tumor volume, gender, basal prolactin levels, bromocriptine resistance or intolerance, and previous treatment with bromocriptine. Even though the present study was not designed to produce a regression model to investigate potential predicting parameters for therapy success, we can confirm that tumor size and prolactin levels are negative factors, since success of cabergoline treatment was higher in microprolactinoma than in macroprolactinoma patients, and both parameters were indeed higher at baseline in patients not achieving prolactin normalization after 6 months of cabergoline treatment (data not shown). In our series gender was irrelevant; although in the series of Verhelst et al. (24) men were reported to have a significantly lower likelihood of achieving normoprolactinemia than women, they also bear a macroprolactinoma more frequently. The age of the patient was also considered to play a role in treatment response since young age $(<30$ years $)$ was reported to be associated with a higher rate of resistance to dopamine agonists in men $(7,35)$. Other results indicated, however, that older ( $>40$ years) women had more aggressive and, presumably, less responsive tumors (6). In our cohort, age was weakly correlated with basal prolactin levels $(r=0.21, P=0.02)$, but not with prolactin levels or tumor size after treatment, nor with the cabergoline dose; thus there was no suggestion of a different sensitivity to cabergoline according to age.

Finally, the outcome of cabergoline treatment in this cohort was lower $(76.3 \%)$ than that generally reported in the literature by us $(4,10-12,23,31,33)$ and others $(24,32,34,36-38)$. However, the present study only reported the data of a short-term course of treatment while most previous studies indicated the outcome of longer treatment periods. Therefore, the outcome should improve in long-term treatment.

\section{References}

1 Colao A \& Lombardi G. Growth hormone and prolactin excess. Lancet 1998352 1455-1461.

2 Carter JN, Tyson JE, Tolis G, Van Vliet S, Faiman C \& Friesen HG. Prolactin-secreting tumors and hypogonadism in 22 men. New England Journal of Medicine 1978299 847-852.

3 Colao A, De Rosa M, Sarnacchiaro F, Di Sarno A, Landi ML, Iervolino E et al. Chronic treatment with CV 205-502 restores the gonadal function in hyperprolactinemic males. European Journal of Endocrinology $1996 \mathbf{1 3 5} 548-552$.

4 De Rosa M, Colao A, Di Sarno A, Ferone D, Landi ML, Zarrilli S et al. Cabergoline treatment rapidly improves gonadal function in hyperprolactinemic males: a comparison with bromocriptine. European Journal of Endocrinology 1998138 286-293.

5 Calle-Rodrigue RD, Giannini C, Scheithauer BW, Lloyd RV, Wollan PC, Kovacs KT et al. Prolactinomas in male and female patients: a comparative clinico-pathology study. Mayo Clinic Proceedings 199873 1046-1052.

6 Pinzone JJ, Katznelson L, Danila DC, Pauler DK, Miller CS \& Klibanski A. Primary medical therapy of micro- and macroprolactinomas in men. Journal of Clinical Endocrinology and Metabolism $2000853053-3057$.

7 Delgrange E, Trouillas J, Maiter D, Donckier J \& Tourniaire J. Sexrelated difference in the growth of prolactinomas: a clinical and proliferation marker study. Journal of Clinical Endocrinology and Metabolism 199782 2102-2107.

8 Colao A, Annunziato L \& Lombardi G. Treatment of prolactinomas. Annals of Medicine $199830452-459$.

9 Molitch ME, Thorner MO \& Wilson C. Management of prolactinomas. Journal of Clinical Endocrinology and Metabolism 199782 996-1000.

10 Colao A, Di Sarno A, Landi ML, Cirillo S, Sarnacchiaro F, Facciolli $\mathrm{G}$ et al. Long-term and low-dose treatment with cabergoline 
induces macroprolactinoma shrinkage. Journal of Clinical Endocrinology and Metabolism 199782 3574-3579.

11 Colao A, Di Sarno A, Landi ML, Scavuzzo F, Cappabianca P, Pivonello $\mathrm{R}$ et al. Macroprolactinoma shrinkage during cabergoline treatment is greater in naive patients than in patients pretreated with other dopamine agonists: a prospective study in 110 patients. Journal of Clinical Endocrinology and Metabolism $2000852247-2252$.

12 Di Sarno A, Landi ML, Cappabianca P, Di Salle F, Rossi FW, Pivonello R et al. Resistance to cabergoline as compared to bromocriptine in hyperprolactinemia: prevalence, clinical definition and therapeutic strategy. Journal of Clinical Endocrinology and Metabolism $2001865256-5261$.

13 Colao A, Cerbone G, Pivonello R, Aimaretti G, Loche S, Di Somma $\mathrm{C}$ et al. The growth hormone $(\mathrm{GH})$ response to arginine plus $\mathrm{GH}$ releasing hormone test is correlated to the severity of lipid profile abnormalities in adult patients with GH deficiency. Journal of Clinical Endocrinology and Metabolism 199984 1277-1282.

14 Colao A, Di Somma C, Pivonello R, Loche S, Aimaretti G, Cerbone $\mathrm{G}$ et al. Bone loss is correlated to the severity of growth hormone (GH) deficiency in adult patients with hypopituitarism. Journal of Clinical Endocrinology and Metabolism 1999 84 1919-1924.

15 Cappabianca P, Lodrini S, Felisati G, Peca C, Cozzi R, Di Sarno A et al. Cabergoline-induced CSF rhinorrhea in patients with macroprolactinoma. Report of three cases. Journal of Endocrinological Investigation 200124 183-187.

16 Somma M, Beauregard H \& Rasio E. Le prolactinome chez l'homme: evaluation préopératoire de 40 patients. Neurochirurgie $19812737-39$

17 Eversmann T, Eichinger R, Fahlbusch R, Rjosk HK \& von Werder K. Die hyperprolaktinämie beim mann: klinik und therapie. Schweiz Medica Wochenschreibe 1981111 1782-1789.

18 Spark RF, Wills CA, O'Reilly G, Ransil BJ \& Bergland R. Hyperprolactinaemia in males with and without pituitary macroadenomas. Lancet 19822 129-132.

19 Hulting AL, Muhr C, Lundberg PO \& Werner S. Prolactinomas in men: clinical characteristics and the effect of bromocriptine treatment. Acta Medica Scandinavica 1985217 101-109.

20 Walsh JP \& Pullan PT. Hyperprolactinaemia in males: a heterogeneous disorder. Australian New Zealand Journal of Medicine 199727 385-390.

21 Grisoli F, Vincentelli F, Jaquet P, Guibout M, Hassoun J \& Farnarier P. Prolactin secreting adenoma in 22 men. Surgical Neurology 1980 $13241-247$

22 Berezin M, Shimon I \& Hadani M. Prolactinoma in 53 men: clinical characteristics and modes of treatment (male prolactinoma). Journal of Endocrinological Investigation 1995 18 436-441.

23 Di Somma C. Colao A. Di Sarno A. Klain M, Landi ML, Facciolli G et al. Bone density and bone marker responses to dopamine agonist therapy in hyperprolactinemia males. Journal of Clinical Endocrinology and Metabolism $1998 \mathbf{8 3} 807-813$.

24 Verhelst J, Abs R, Maiter D, Vandeweghe M, Velkeniers B, Mockel J et al. Cabergoline in the treatment of hyperprolactinemia: a study in 455 patients. Journal of Clinical Endocrinology and Metabolism $1999842518-2522$.
25 Lachelin GCL, Abu-Fadil S \& Yen SSC. Functional delineation of hyperprolactinaemic amenorrhea. Journal of Clinical Endocrinology and Metabolism 199744 1163-1174.

26 Nunes MCP, Sobrinho LG, Calhaz-Jorge C, Santos MA, Mauricio JC \& Sousa MF. Psychosomatic factors in patients with hyperprolactinaemia and/or galactorrhea. Obstetrics and Gynecology $1980 \mathbf{5 5} 591-595$.

27 Cohen LM, Greenberg DB \& Murray GB. Neuropsychiatric presentation of men with pituitary tumors (the 'four As'). Psychosomatics 198425 925-928.

28 Creemers LB, Zelissen PMJ, van't Verlaat JW \& Koppeschaar HPF. Prolactinoma and body weight: a retrospective study. Acta Endocrinologica $1991125392-396$.

29 Delgrange E, Donckier J \& Maiter D. Hyperprolactinemia as a reversible cause of weight gain in male patients? Clinical Endocrinology $1999 \mathbf{5 0} 271-272$.

30 Greenman Y, Torjman K \& Stern N. Increased body weight associated with prolactin secreting pituitary adenomas: weight loss with normalization of prolactin levels. Clinical Endocrinology $1998 \mathbf{4 8} 547-553$.

31 Colao A, Di Sarno A, Sarnacchiaro F, Ferone D, Di Renzo GF, Merola B et al. Prolactinomas resistant to standard dopamine agonists respond to chronic cabergoline treatment. Journal of Clinical Endocrinology and Metabolism 199782 876-883.

32 Biller BMK, Molitch ME, Vance ML, Cannistraro KB, Davis KR, Simons JA et al. Treatment of prolactin-secreting macroadenomas with the once-weekly dopamine agonist cabergoline. Journal of Clinical Endocrinology and Metabolism 199681 2338-2343.

33 Colao A, Loche S, Cappa M, Di Sarno A, Landi ML, Sarnacchiaro F et al. Prolactinomas in children and adolescents. Clinical presentation and long-term follow-up. Journal of Clinical Endocrinology and Metabolism $1998 \mathbf{8 3} 2777-2780$.

34 Cannavò S, Curtò L, Squadrito S, Almoto B, Vieni A \& Trimarchi F. A first choice treatment in patients with previously untreated prolactin-secreting pituitary adenoma. Journal of Endocrinological Investigation 199922 354-359.

35 Delgrange E, Maiter D, Donckier J \& Tourniaire J. Influence of age on the clinical presentation of prolactinomas in male patients. Gerontology $1999 \mathbf{4 5} 160-164$.

36 Webster J. Piscitelli G, Polli A, Ferrari CI, Ismail I \& Scanlon MF. A comparison of cabergoline and bromocriptine in the treatment of hyperprolactinemic amenorrhoea. New England Journal of Medicine $1994331904-909$.

37 Ferrari CI, Abs R, Bevan JS, Brabant G, Ciccarelli E, Motta T et al. Treatment of macroprolactinoma with cabergoline: a study of 85 patients. Clinical Endocrinology 199746 409-413.

38 Muratori M, Arosio M, Gambino G, Romano C, Biella O \& Faglia G. Use of cabergoline in the long-term treatment of hyperprolactinemic and acromegalic patients. Journal of Endocrinological Investigation $1997 \mathbf{2 0} 537-546$.

Received 7 June 2002

Accepted 15 November 2002 